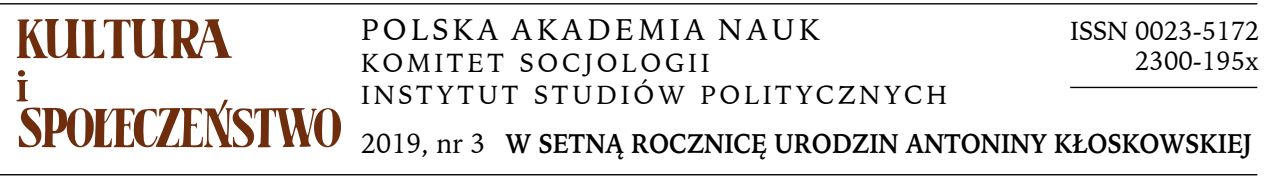
$\begin{array}{llllllll}A & R & T & Y & K & U & £ & Y\end{array}$
I
$\begin{array}{llllllll}\mathrm{R} & \mathrm{O} & \mathrm{Z} & \mathrm{P} & \mathrm{R} & \mathrm{A} & \mathrm{W} & \mathrm{Y}\end{array}$

EWELINA WEJBERT-WĄSIEWICZ

Uniwersytet Łódzki

\title{
ŁÓDZKA SZKOŁA SOCJOLOGII KULTURY: OD BADAŃ ODBIORU SZTUK WERBALNYCH DO SZTUK WIZUALNYCH*
}

\section{WPROWADZENIE}

Zamierzam ukazać dorobek empirycznej szkoły socjologii kultury w perspektywie istotnych zagadnień semiotycznych. Na przykładzie wybranych prac wybitnej uczonej Antoniny Kłoskowskiej i „łódzkiej szkoły", którą stworzyła, podejmę próbę odpowiedzi na następujące pytania: Jak kształtowało się podejście teoretyczno-metodologiczne do badań kultury symbolicznej? Co charakteryzowało praktykę badań łódzkiej szkoły socjologii kultury? Z jakimi problemami mierzyli się badacze? Ostatnie zagadnienie zostanie osadzone w kontekście badań dotyczących odbioru filmowego (wyjdę od empirycznych ustaleń Antoniny Kłoskowskiej dotyczących ekranizacji Wesela).

Przez kilka dekad ubiegłego wieku semiotyczne podejście wzbogacało socjologię kultury. Semiologowie inspirowali socjologów głównie ze względu na perspektywę semiotyczną ukierunkowaną na dociekanie

Adres do korespondencji: ewelina.wejbert@uni.lodz.pl; ORCID: 0000-0002-6711-8228

* Pierwotna mniej rozbudowana wersja tego tekstu pt. Znak w filmie była referowana na konferencji naukowej z okazji setnej rocznicy urodzin Profesor Antoniny Kłoskowskiej „Kultura i znaki”, zorganizowanej w Instytucie Socjologii Uniwersytetu Łódzkiego, dnia 23 maja 2019 r. 
znaczenia badanej rzeczywistości. Z kolei uczynienie kwestii znaczenia centralnym przedmiotem badań socjologicznych wymagało zakorzenienia $\mathrm{w}$ teorii oraz włączenia metod semiotycznych (interpretacja, analiza języka) $\mathrm{w}$ repertuar użytecznych narzędzi badawczych. Moje indywidualne zainteresowania ogniskują się wokół socjologii filmu i pragnę wykazać, że proces autonomizacji empirycznej pola socjologii filmu dokonywał się dzięki inspiracjom semiotyki oraz socjologii literatury. Stąd w tytule pojawia się fraza: od sztuk werbalnych do sztuk wizualnych. Literatura i film to odmienne systemy semiotyczne, można jednak z powodzeniem nakreślić tu paralele, koegzystencje i wspólne dylematy odrębnych ontologicznie sztuk (zob. Has-Tokarz 2007). Warto dodać, że socjologia literatury i filmu mierzyły się z podobnymi problemami teoretycznymi i metodologicznymi (por. Sławiński 1971; Żygulski 1966; Mencwel 1977; Markiewicz 1976). A badacze $z$ kręgu socjologii filmu czerpali inspiracje $z$ socjologii literatury.

Semiotyka filmu i socjologia filmu jako nauki stosowane zaczęły się rozwijać coraz bardziej mniej więcej w tym samym czasie, w początkach lat sześćdziesiątych XX wieku ${ }^{1}$. Semiotyka filmu na dobre powstała w 1960 roku za sprawą tekstu Rolanda Barthes'a pt. Problem znaczenia $w$ filmie (Helman, Ostaszewski 2007, s. 191-192). Barthes szukał systemowych zasad organizacji języka filmu, czerpiąc inspiracje $z$ koncepcji Ferdinanda de Saussure'a (między innymi podział na langue i parole, signifiant i signifié). Z kolei dla semiologów spod znaku semiotyki logicznej chrakterystyczna była koncepcja triadyczna znaku (reprezentamen, przedmiot znaku, interpretant) oraz logiczna klasyfikacja znaków Charlesa Sandersa Peirce'a (Helman, Ostaszewski 2007, s. 196-199). Semiotycy filmu skupili się na kluczowych kwestiach: znaku filmowego, języka filmu², filmu jako zjawiska znakowego. Antonina Kłoskowska w empirycznych badaniach socjologicznych sięgała do semiotyki w ujęciu teoretycznym. Jej podejście kontynuowali w wielu publikacjach współpracownicy i uczniowie. Film nie zajmował w jej zainteresowaniach naukowych szczególnej pozycji.

${ }^{1}$ Obie wspomniane dyscypliny kształtowały się na obrzeżach odpowiednich pól naukowych, semiotyka filmu jako perspektywa filmoznawcza inspirowana językoznawstwem, lingwistyką strukturalną, a także logiką Charlesa Sandersa Peirce'a, socjologia filmu zaś jako socjologia szczegółowa, pogłębiająca wiedzę naukową o filmie. W Polsce Historię semiotyki filmu w dwóch tomach przedstawiła Alicja Helman wraz ze współpracownikami (Andrzej Gwóźdź, Tadeusz Miczka, Jacek Ostaszewski) (zob. Helman 1991, 1993).

2 Wśród najbardziej znanych orędowników koncepcji języka filmu (kodu filmu) można wymienić Rolanda Barthes'a, André Bazina, Christiana Metza, Umberta Eco, Jurija Łotmana, Jurija Cywiana, Siergieja Eisensteina, Pierre'a Paolo Pasoliniego, Sola Wortha i wielu innych teoretyków oraz artystów (zob. Helman 1976; 1992). 


\section{ZNAKI W UJĘCIU ANTONINY KŁOSKOWSKIEJ}

Kluczowe dla semiologów pojęcie znaczenia, znaku nie jest proste (zob. Plesnar 1990, s. 7-50; Helman, Ostaszewski 2007, s. 199-207; Hendrykowski 2014, s. 30-32; Pelc 1982), a więc socjologom tym bardziej może wydać się zawiłe, obudowane hermetycznymi teoriami i słownictwem. Wypada dodać, że wspólnym elementem teorii semiotycznych jest relacjonalny charakter znaku (związek między znaczącym i oznaczanym), ale obraz komplikuje różnorodność w definiowaniu terminów, niejednolitość zasad podziałów klasyfikacji znaków. Antonina Kłoskowska w Socjologii kultury (1983, s. 129-171) porusza się w wielości tych zagadnień i podejmuje trud opracowania semiotycznego kryterium kultury symbolicznej. W jej rozumieniu socjologia kultury zajmować się powinna zjawiskami semiotyczno-symbolicznymi. Koncepcja znaku i semiozy miała służyć socjologom poprzez operacjonalizację i zastosowanie w badaniach empirycznych. Szeroko rozumiany znak „zastępuje dla kogoś coś innego, czym sam nie jest" (Kłoskowska 1983, s. 129). Główne kryteria różnorodnych klasyfikacji znaków to pytanie o źródło znaku, o sposób jego ukonstytuowania, o związek z oznaczanym, o substancję znaku (zob. Kłoskowska 1983, s. 147; Pelc 1982, s. 192, 176-177).

Prace semiotyków pokazywały, że nie ma czystych, jednorodnych użyć znaków, a wszelkie ich podziały są względne. Symbole i znaki ikoniczne - funkcjonujące $\mathrm{w}$ wielu klasyfikacjach jako odrębne, a nawet przeciwstawne - to swoiste amalgamaty (zob. Pelc 1982, s. 182-184). Kłoskowska przy opracowywania własnej charakterystyki znaków czerpała inspirację z typologii Charlesa S. Peirce'a, z rozważań Adama Schaffa oraz $z$ antropologicznej typologii znaków Edmunda Leacha, lecz zastosowała inne zasady podziału znaków niż ci autorzy ${ }^{3}$. Ze względu na kryterium naturalności znaki podzieliła na: oznaki, znaki konwencjonalne, znaki ikoniczne. Te ostatnie uznała za odrębny typ (Kłoskowska 1983, s. 135), podobnie jak Peirce, Morris, Eco i inni autorzy (zob. Plesnar 1990, s. 27-35; Pelc 1982, s. 142-150). Wśród znaków konwencjonalnych wyodrębniła $z$ uwagi na funkcje: sygnały, znaki właściwe, znaki przydane. A same znaki właściwe w kulturze symbolicznej pogrupowała według nośnika przekazu: język, znaki motoryczne i kinetyczne, zna-

\footnotetext{
${ }^{3}$ Praktyczne zastosowanie jakiejkolwiek typologii znaku wymaga wiedzy o istnieniu poszczególnych orientacji teoretycznych i gatunków znaków, wzięcia pod uwagę rozbieżnych tendencji w ujmowaniu relacji symboli i znaków ikonicznych (zob. Pelc 1982, s. 140-174). Kłoskowska (1983, s. 149-153) dostrzegła skomplikowaną sytuację różnorodności i zmienności funkcji w kulturze bytu i w porządku kultury symbolicznej.
} 
ki plastyczne i graficzne, znaki dźwiękowe, znaki przedmiotowe, czyli symbole (Kłoskowska 1983, s. 148). Ta charakterystyka znaków okazała się przydatna dla socjologów kultury i sztuki. Koncepcja znaku w ujęciu Kłoskowskiej była szeroko stosowana przez łódzką szkołę socjologii kultury.

\section{W KRĘGU BADAŃ NAD ODBIOREM KULTURY SYMBOLICZNEJ}

Zjawiska odbioru społecznego kultury zajmowały łódzkich socjologów kultury i sztuki przez półwiecze i niewątpliwie działo się to za sprawą mistrzyni polskiej socjologii kultury. Antonina Kłoskowska swoje empiryczne zainteresowania ogniskowała wokół polskiej kultury narodowej i odbioru jej kanonu. Wiele czerpała z dziedzictwa myśli Józefa Chałasińskiego i Stanisława Ossowskiego oraz filozofii Romana Ingardena. Kulturę symboliczną analizowała od lat pięćdziesiątych ubiegłego wieku. Szczególnie wiele uwagi poświęcała literaturze. Projektowała i realizowała badania recepcji twórczości Adama Mickiewicza, Stefana Żeromskiego, Stanisława Wyspiańskiego. Wychowankowie Antoniny Kłoskowskiej rozwijali i stosowali proponowane przez nią podejście teoretyczne i empiryczne do badania autotelicznej kultury symbolicznej oraz różnych jej aspektów (np. kultury narodowej, kanonu kultury narodowej, kultury popularnej i zabawy) ${ }^{4}$. Spośród bogatego dorobku naukowego tego grona wymienię tu tylko niektóre prace naukowe, wybrane selektywnie i subiektywnie, w mojej opinii najważniejsze i wskazujące na swoiste ukierunkowanie „łódzkiej szkoły socjologicznej".

Bogusław Sułkowski, doktorant Antoniny Kłoskowskiej, stosunkowo wcześnie podjął wyjątkowo udaną próbę dotarcia do przeżyć odbiorców literatury, ich nastawienia na treści i jakości bohatera. W badaniu, na którym oparł swoją analizę, respondentom zaproponowano lekturę dwóch powieści, a następnie zostali poddani dwuetapowej procedurze: najpierw wypełniali test wiedzy o literaturze, a potem przeprowadzano $z$ nimi wywiad swobodny rejestrowany. W Przedmowie do książki Sułkowskiego (1972, s. 12) Kłoskowska ocenia, że szczególną zaletą takiego podejścia jest opracowanie analizy odbioru różnych warstw dzieła literackiego. Inna

\footnotetext{
${ }^{4}$ Antonina Kłoskowska funkcję kierownika Katedry Historii Socjologii i Myśli Społecznej na Uniwersytecie Łódzkim pełniła od 1961 roku, a od 1970 roku kierowała Zakładem Socjologii Kultury. Wśród grona jej uczniów znaleźli się wówczas między innymi: Zbigniew Bokszański, Kazimierz Kowalewicz, Alicja Rokuszewska-Pawełek, Mieczysław Marciniak, Andrzej Piotrowski, Bogusław Sułkowski, Janina Tobera.
} 
doktorantka, Alicja Rokuszewska-Pawełek, kontynuowała zainteresowania recepcją literatury pięknej, a świadectwem tego jest rozprawa pt. Potoczny odbiór literatury popularnej na przykładzie społecznej recepcji powieści kryminalnej (1983), a także późniejsze prace. Oprócz literatury łódzcy socjologowie, wychowankowie Antoniny Kłoskowskiej, na warsztat empirycznych dociekań wzięli także odbiorców kultury masowej (Sułkowski 1984; Gałuszka 1996). Mieczysław Gałuszka najdłużej spośród łódzkich badaczy zajmował się recepcją filmu. Zarazem wraz z Kazimierzem Kowalewiczem badał też szerzej zagadnienia odbioru kultury artystycznej, między innymi recepcję muzyki (kilkanaście współautorskich artykułów naukowych z lat siedemdziesiątych-osiemdziesiątych). Teatr i odbiór przedstawień teatralnych analizował Kowalewicz, poświęcając temu zagadnieniu kilkanaście rozpraw oraz monografię Teatr i odbiorca (Kowalewicz 1993). Tradycje semiotycznie zorientowanych, jakościowych socjologicznych badań odbioru na tym polu w XXI wieku kontynuowała Emilia Zimnica-Kuzioła (2003). Z kolei kwestiom recepcji sztuk plastycznych poświęciła swoje prace Anna Matuchniak-Krasuska $(1988,1999)$. Książka Publiczność wobec metafory plastycznej. O recepcji groteski Jerzego Dudy-Gracza (Matuchniak-Krasuska 1999) była dedykowana Profesor Antoninie Kłoskowskiej. Koncepcje metafory wizualnej zaprezentowane w tej teoretyczno-empirycznej rozprawie dotyczącej groteski w malarstwie oraz kody rozpoznania znaków i konwencji mogą stanowić źródło inspiracji dla badaczy sztuk wizualnych oraz odbioru treści. Fenomenologia, hermeneutyka i semiotyka (obok estetyki) to perspektywy komplementarnie stosowane w badaniach recepcji prowadzonych przez Antoninę Kłoskowską i przywołanych badaczy. Wspólnym rysem badań „szkoły łódzkiej” pozostaje operacjonalizacja pojęcia odbioru kultury i sztuki.

„Odbiór dzieła” to termin szeroki, odnoszący się do różnorodnych form reakcji na przekaz, w tym do przeżyć percepcyjnych (jak wywołane emocje, przemyślenia, refleksje natury psychologicznej czy egzystencjalnej). Wyróżniono dwa główne typy odbioru: krytyczny, wąski i profesjonalny oraz potoczny, szeroki, niejednorodny. Z kolei „rozumienie utworu” odnosi się do rozpoznania przez aktywnego odbiorcę dosłownego znaczenia, sensu dzieła, a „interpretacja” oznacza wychodzenie przez odbiorcę poza dosłowne sensy i to, co dane bezpośrednio w dziele. Zadaniem socjologa badającego ten ostatni aspekt odbioru jest zdanie relacji z intelektualnej analizy dzieła (zob. Kłoskowska 1976, s. 68; Sułkowski 1972, s. 134-143; Matuchniak-Krasuska 1984). Z interpretacją filmu wiąże się znany w teorii podział na film metaforyczny i metonimiczny (np. wedle Karola Irzykowskiego, Romana Jakobsona, Rolanda Barthes'a). Film metaforycz- 
ny przesłania rzeczywistość znakiem i sugeruje znaczenie intelektualne. W filmie metonimicznym znak służy jako symulacja obrazu rzeczywistości.

Socjologiczne badania nad odbiorem kultury i sztuki są związane $z$ teorią sztuki, estetyką i z semiotyką. Istotne źródła inspiracji dla socjologów to semiotyka Umberta Eco (koncepcja organizmu artystycznego i dzieła otwartego), filozofia hermeneutyczna Paula Ricoeura, Hansa Georga Gadamera (rola przedsądów w procesie interpretacji, koło hermeneutyczne - droga rozumienia od całości do części i z powrotem). Chodzi tu o nastawienie na odbiorcę, dowartościowanie potocznego odbioru, społeczne wartościowanie sztuki, każdej recepcji dzieła, gdyż wówczas dzieło odżywa na nowo (zob. Ricoeur 1975, Gadamer 2004; Eco 1972; Kłoskowska 1983, s. 410-422). Odpowiednikiem terminu „odbiór” bywa właśnie pojęcie „recepcji”, czasem do pewnego stopnia obarczone psychologicznym zabarwieniem. Socjologowie używają tego terminu w węższym rozumieniu. Recepcja sztuki jest elementem komunikowania. Determinuje ją wiele czynników (np. kompetencje intelektualne, gust i aspiracje, różnorodność dostępnych treści kulturowych i inne). Badania łódzkich socjologów pozwoliły określić rodzaje interpretacji (np. metaforyczna, dosłowna, uogólniająca), poziomy i style odbioru (np. mimetyczny, formalny, ekspresyjny) (zob. Sułkowski 1972, s. 137-138; Matuchniak-Krasuska 1988, s. 87-142) oraz różnorodne typy obiorców (Kowalewicz 1993; Zimnica-Kuzioła 2003).

\section{INSPIRACJE TEORETYCZNE}

W empirycznych badaniach łódzkich socjologów dotyczących odbioru kultury symbolicznej najczęściej wykorzystywano intencjonalną teorię znaczenia, teorię i schemat pola semantycznego, fenomenologiczną koncepcję dzieła Romana Ingardena (1972), myśl Jurija Łotmana, a także socjologię sztuki Stanisława Ossowskiego ${ }^{5}$. Przedstawię tu tylko wyimki pewnych koncepcji, które inspirowały Antoninę Kłoskowską i grono jej uczniów — badaczy odbioru kultury symbolicznej. W przypadku badań odbioru dzieł było to zwłaszcza Ossowskiego pojęcie wartości estetycznej ${ }^{6}$,

\footnotetext{
${ }^{5}$ Antoninę Kłoskowską cechowało szczególne przywiązanie do myśli Stanisława Ossowskiego, czemu wprost dawała wyraz w swoich pracach, co po latach jej uczniowie (np. Bokszański 2012, s. 50) potwierdzają, analizując charakterystyczne stanowisko „socjologii kulturalistycznej” na kartach poświęconego jej numeru „Przeglądu Socjologicznego” (2012, nr 3).

${ }^{6}$ Jest to suma przeżyć i procesów emocjonalnych wywołanych odbiorem dzieła.
} 
ekspresji czynnej i biernej ${ }^{7}$. Do sytuacji odbiorczej odnoszono „niedookreślenie" Ingardena. Czytelnik, widz, odbiorca dzieła dokonuje konkretyzacji, przyobleka dzieło $\mathrm{w}$ ciało. W ten sposób zadanie widza zawsze polega na rozpoznaniu znaków, na dopasowaniu tego, co słyszy i widzi, do znanych mu już wyobrażeń.

Roman Ingarden (1972, s. 203), autor fenomenologicznej koncepcji filmu, cytowany i uznawany przez Kłoskowską, zawęził film fabularny do dzieła sztuki różniącego się od filmów naukowych, edukacyjnych czy reportaży. Odnosząc Ingardenowskie „niedookreślenie” do filmu, można stwierdzić, że dzieło montuje nie tylko autor, ale nieustannie także widz w swoim umyśle, w swojej głowie (zob. Hendrykowski 2014, s. 84). Tworzy - czy też "zszywa” - pewną strukturę znakową, budują ją bowiem nie tylko poszczególne ujęcia, ale wszystko co widzialne i słyszalne, co pojawia się na ekranie oraz nie pojawia, ale zostało pomyślane (Hendrykowski 2014, s. 86-87). Utwór filmowy nie jest gotową konkretyzacją, widz $\mathrm{w}$ procesie odbioru, korzystając $\mathrm{z}$ wyobraźni, wypełnia liczne puste miejsca (Hendrykowski 2014, s. 117). Bez strumienia uczuć i myśli nie jest możliwy odbiór filmu, gdyż brakuje wtedy przeżycia i zrozumienia, a to stanowi istotę pełnego procesu komunikacji między nadawcą a odbiorcą. Według Ingardena widz w procesie obioru „filmów artystycznych” (sztuki) i „filmów reportażowych” (nie-sztuki) doświadcza różnych oddziaływań. Filozof podkreślał, że żadna sztuka nie jest w stanie pokazać tak jak film losu człowieka, w konkretnym czasie i miejscu (Ingarden 1972, s. 218). Ta świadomość naoczności sztuki kinematograficznej pojawiła się w refleksji teoretycznej już u zarania istnienia kina.

Odbiorowi filmu towarzyszy zjawisko mowy wewnętrznej, jak zauważył rosyjski literaturoznawca Boris Eichenbaum, a podtrzymywał Eisenstein (zob. Łotman 2008, s. 26). Takie zjawisko autokomunikacji - czy można by rzec: „dyskursu wewnętrznego” — interesowało Jurija Łotmana. Mówi on o komunikowaniu sobie samemu (zapiski w dzienniku, uciekanie do tekstów, mów, rozmyślań z samym sobą, oglądanie filmu) (Łotman 2008, s. 97). Według Antoniny Kłoskowskiej (1983, s. 291-294; 431-432; 476-479) jest to w części model kultury utajonej, możliwy do poznania na zasadzie introspekcyjnych relacji. Procesy semiozy w tym wariancie są wewnętrzne, intersubiektywnie niedostępne, przebiegają w świadomości uczestników.

7 Ekspresja bierna w rozumieniu Stanisława Ossowskiego oznacza odtworzenie stanu wyrażanego przez artystę (intelektualne i artystyczne skupienie), a ekspresja czynna zachodzi, gdy jednostka nakłada własne sądy o świecie na dzieło. 
Łotmanowski obraz kultury składał się z trzech płaszczyzn: „góry” reprezentowanej przez wtórne systemy, środka — pola języka naturalnego, i dołu - charakterystycznego dla życia codziennego, świata zachowań, rzeczy i techniki, czyli bytu (Łotman 2008, s. 15). Należy zaznaczyć, że układ ten, zanurzony w semiosferze, nie był - jego zdaniem - czymś statycznym. Łotman uważał, że „teksty artystyczne” pełnią dwie funkcje: komunikacyjną, służącą porozumiewaniu się, oraz modelującą, zawierającą określny obraz świata. Obie są ważne z punktu widzenia socjologa sztuki. Socjologiczne badania sztuki skupiają się na czterech zasadniczych elementach: dziele sztuki i jego recepcji, artyście i procesie tworzenia, kategoriach odbiorców oraz instytucjonalnych, społecznych ramach sztuki. Komunikacja artystyczna na linii nadawca-odbiorca została opisana przez wielu teoretyków (np. Umberto Eco, Andrew Tudor, Vladimir Karbusický). Szeroko stosowany był model Romana Jakobsona, który rozbudował schemat komunikacji Karla Bühlera, sięgając do funkcjonalnej analizy kultury triobriandzkiej Bronisława Malinowskiego (zob. Kłoskowska 1976, s. 85). Aparat ten był szeroko wykorzystywany także przez semiotyków. To, co przekształca komunikat językowy w dzieło artystyczne, bada nauka zwana poetyką. Jakobson (1960), przypomnijmy, przypisał poszczególne funkcje elementom procesu komunikacji, takim jak nadawca, odbiorca, desygnat, kod, kontakt. Koncentracja na nadawcy uwypukla funkcję emotywną lub ekspresyjną, na odbiorcy - konatywną lub apelatywną, na desygnacie - referencyjną (lub poznawczą), na kodzie - funkcję metajęzykową, na kontakcie - funkcję fatyczną, na sposobie wypowiedzi funkcję poetycką, estetyczną. W świetle badań recepcji dzieł ta ostatnia najmniej zaznacza się w potocznym odbiorze, co nie znaczy że nie realizuje się w faktycznym oddziaływaniu na odbiorców (Kłoskowska 1983, s. 414). Antonina Kłoskowska w Socjologii kultury (1983, s. 278) również nawiązuje do tej propozycji, wskazując na jej użyteczność i zastosowanie do badania wszelkich przekazów symbolicznych.

Uczeń Kłoskowskiej, Mieczysław Gałuszka (1984b), sięgnął po schemat Jakobsona i perspektywę semiotycznej socjologii kultury w rozprawie na temat społecznej recepcji filmu Amator z 1979 roku. W teorii dotyczącej filmu istnieje trójczłonowe rozróżnienie na: (a) „film-taśmę”, „filmowy zapis" odnoszony się do materialnej i gotowej wersji filmu dzieła; (b) „film-projekcję" - dzieło oglądane przez widza; (c) „film-analizę" (zob. Jackiewicz 1975, s. 22-23; por. Aumont, Marie 2012, s. 70). Aleksander Jackiewicz zakładał, że należy badać tylko dzieło — jako autonomiczny, gotowy przedmiot, a Jurij Łotman w Semiotyce filmu (1983, s. 99) pisał, że każdy utwór należy do frontu ideologicznego, do kultury i sztuki swej 
epoki, a znaczenie filmowe to znaczenie wyrażane środkami języka filmowego i poza tym językiem niemożliwe. Celem sztuki każdego rodzaju nie jest proste odzwierciedlenie jakiegoś obiektu, lecz uczynienie z niego nosiciela znaczenia. Gałuszka zajął się filmem oglądanym, odbieranym, rozumianym, postrzeganym, zapamiętanym i przeżywanym przez widza. Nie deprecjonując żadnego ujęcia filmu i odnosząc się do praktyki badawczej, wypada stwierdzić, że ten wymiar pozostaje najważniejszym dla socjologa. Takie stanowisko zajęła nie tylko „łódzka szkoła” socjologii kultury (zob. Kłoskowska 1983, s. 430-440; Żygulski 1966; Koprowska 1986; Gałuszka, Kowalewicz 1977, 1979; Gałuszka 1984a; 1996; Grad 1997; Wejbert-Wąsiewicz 2017, s. 23-29).

Nie omawiam tutaj inspiracji związanych $z$ teoriami znaczenia, jak teoria asocjacyjna, teoria intencjonalna, teoria biologiczna, teoria konotacyjna, teoria weryfikacyjna (zob. Pelc 1982, s. 227-303). Nie wszystkie znaczenia ${ }^{8}$ interesowały socjologów. Badacze filmu koncentrowali uwagę na znaczeniu pragmatycznym, referencyjnym, wartościującym, stosunkowo rzadko - semantycznym. Znaczenie semantyczne filmu odsłaniał wspomniany już Gałuszka, sięgając w badaniach do koncepcji pola semantycznego (np. Gałuszka 1996). Wypada podkreślić, że wpływ na empiryczną socjologię kultury i sztuki miała intencjonalna teoria znaczenia ${ }^{9}$. Wedle tego ujęcia znaczenie to wytwór przeżycia, pewnej czynności świadomościowej. Nie jest ono ponadczasowe, lecz intencjonalne i ma początek w psychice jednostki.

\section{O WYNIKACH BADAŃ NAD ODBIOREM FILMOWYM}

Antonina Kłoskowska tylko raz przedmiotem swoich badań uczyniła film. W 1977 roku wraz z Alicją Rokuszewską-Pawełek podjęła pogłębioną analizę potocznego odbioru filmowej wersji dramatu Wesele (reż. Andrzej Wajda) w celowo dobranej grupie robotników, techników, inży-

${ }^{8}$ Na przykład Łukasz Plesnar (1990, s. 108-154), semiotyk filmu, szeregując i omawiając szczegółowo dziesięć kategorii znaczeń filmowych, wskazuje na znaczenia: syntaktyczne, semantyczne, pragmatyczne, formatywne, referencyjne, inicjujące, wartościujące, dyrektywalne, ekspresywne i ewokatywne, kontaktywne.

${ }^{9}$ Za ojca intencjonalnej teorii znaczenia należy uznać Franza Brentano, a za dalszych kontynuatorów teorii jego uczniów: Kazimierza Twardowskiego oraz Edmunda Husserla. Roman Ingarden, uczeń obu tych uczniów, zmodyfikował teorię, wydzielając przedmioty czysto intencjonalne oraz przedmioty także intencjonalne. Zaproponował również typ przedmiotów intersubiektywnych, dostępnych wielu podmiotom poznającym. Szerzej o tych różnicach pisał Jerzy Pelc (1982, s. 289-294). 
nierów w wieku 22-25 lat oraz humanistów. Wówczas efekty badań nad odbiorem Wesela były dla badaczek wysoce rozczarowujące. Okazało się, że sens dramatu nie dotarł do większości badanych (Kłoskowska, Rokuszewska-Pawełek 1977; por. Kłoskowska 1992, s. 215-228). Wesele było dla Antoniny Kłoskowskiej ważną i wysoko cenioną lekturą. Zachowało się jej wypracowanie na temat dramatu jako uczennicy drugiej klasy liceum (zob. Matuchniak-Krasuska 2012, s. 21-22). Warto w tym miejscu przywołać wywiad, jakiego Antonina Kłoskowska udzieliła Janowi Olszewskiemu ponad czterdzieści lat temu. Został on opublikowany w czasopiśmie „Film” pt. Próba bilansu (1978). Stanowi interesujące świadectwo jej poglądów oraz jest dokumentem ówczesnego czasu.

Rozmowa z krytykiem filmowym dotyczyła ogólnej oceny sytuacji w kulturze, ale także uczestnictwa Polaków w kulturze. Dziennikarz pytał uczoną o pozycję kultury narodowej i ludowej. Podjął kwestię wpływu filmu na sytuację kulturalną naszego społeczeństwa. Antonina Kłoskowska uznała film „za kanał przekazu o najszerszym zasięgu oddziaływania” (miała na myśli zarówno film kinowy, jak i telewizyjny). W rozmowie zachowała powściągliwość $\mathrm{w}$ ocenie zjawiska homogenizacji kultury, powróciła do swoich, wspomnianych przeze mnie, badań filmu:

„Wyniki przekonały nas, że bez starannego przygotowania literackiego i historycznego Wesele wywołuje liczne nieporozumienia. Nie chodzi nawet o to, że widzowie $z$ trudem rozpoznawali strukturę formalną dramatu, niepokojąca była interpretacja faktów i postaci historycznych. O Szeli mówiono, że to powstaniec-patriota, co zginął za ojczyznę; o Wernyhorze że to bojownik o prawa dla biednych. Symboliczną scenę z toczącymi się głowami interpretowano niekiedy w sposób następujący: film pokazuje co burżuazja robiła z chłopami [...]" (Olszewski 1978, s. 42).

Antonina Kłoskowska uwypukliła problem niezrozumienia, nieporozumienia zaznaczające się $\mathrm{w}$ odbiorze filmu przez młodych dorosłych, a nawet wypaczenia treści dramatu, który należy do szkolnego kanonu literaturowego. Po latach w Socjologii kultury znalazły się rozproszone uwagi na temat zubożenia treści dzieła czy niepełnego odbioru (Kłoskowska 1983, s. 489-490). Sprawy te można próbować wyjaśniać na gruncie teorii filozoficznych, fenomenologicznych i semiotycznych (np. Ingarden, Gadamer, Ricoeur, Eco) ${ }^{10}$.

\footnotetext{
10 Alicja Rokuszewska-Pawełek w trakcie konferencji „Kultura i znaki” w dyskusji na temat badania odbioru Wesela (Kłoskowska, Rokuszewska-Pawełek 1977) wyraziła przypuszczenie, iż współcześnie powtórzone badania mogłyby ukazać odmienne wnioski, a jednocześnie oceniła, że jej stosunek do ówczesnych wyników uległ zmianie. Chodzi o złagodzenie kry-
} 
Na rozumienie filmu wpływ mają kompetencje kulturowe i społeczne, dotychczasowe doświadczenia odbiorcze, zaangażowanie w odbiór, sytuacja odbiorcza (zob. Ostaszewski 1999, s. 78; Skowronek 2007, s. 230-233; Wejbert-Wąsiewicz 2017, s. 120-158). Ogólnie można założyć, iż film zawsze jest „mniej więcej” odczytany, bo zawiera bardzo wiele elementów znaczących. Christian Metz twierdził nawet, że można zrozumieć film, lecz nie wiedzieć, o czym on mówi (zob. Jackiewicz 1975, s. 48). Nierzadko na podstawie wywiadów socjologicznych możemy zaobserwować czy ustalić jedynie funkcję referencjalną dzieła. Według Ingardena (1958) odbiór dzieła filmowego może polegać na uzupełnieniu, dookreśleniu jego warstw, ale bywa także zubożeniem, pominięciem jakichś funkcji, niedostrzeżeniem pewnej warstwy czy elementów.

Socjologiczne badania nad recepcją „ruchomych obrazów” uwiarygodniają przekonanie, że możliwy jest opis filmu słowami, odczytanie znaczeń dzieła $\mathrm{w}$ języku werbalnym. Jednakże badania jakościowe tego typu wiążą się ze specyficznymi problemami, których badacze są na ogół świadomi (zob. Kłoskowska 1992, s. 226-227; Hendrykowski 2014, s. 56-57). W latach siedemdziesiątych ubiegłego wieku problemem odbioru filmowego zajmowali się Kazimierz Kowalewicz i Mieczysław Gałuszka. Kreśląc program badawczy zwracali oni uwagę na mechanizmy determinujące procesy odtworzenia i bariery zakłócające odbiór (Gałuszka, Kowalewicz 1977, s. 31, 1979; Kowalewicz 1978).

Dla badaczy zorientowanych na perspektywę potocznego widza kluczową niedogodnością pozostaje selektywna pamięć odbiorców. Z tego powodu należy odróżniać praktyczne uczestnictwo w projekcji filmowej od poziomu relacji o filmie, od poziomu relacji o interpretacji, stanowiących „pamięć o widowisku” (Gałuszka, Kowalewicz 1988). Na ten aspekt badań nad recepcją zwracali uwagę różni autorzy w odniesieniu do literatury, filmu kinowego czy telewizyjnego (zob. Kłoskowska 1976, s. 77; Koprowska 1986; Golka 1996, s. 185-186; Wejbert-Wąsiewicz 2017, s. 152-154). W wywiadach, ankietach czy testach wiedzy o dziele i twórcach przedmiot analizy ostatecznie stanowią zawsze deklaracje respondentów. Brak odpowiedzi nie oznacza całkowitej niewiedzy, lecz to, że poruszony problem nie stanowi aktywnego elementu wyposażenia świadomości w danym momencie (zob. Kłoskowska 1976, s. 77; por. Sułkowski 1984, s. 73, s. 148-149).

tycznego tonu wobec respondentów. Badaczka uznała, że niekiedy uboższa w słowa relacja o filmie niesie głębsze przesłanie, odmienne postrzeganie faktów uwydatnia coś innego, odarcie dzieła $z$ jakiegoś elementu transformuje jego znaczenie. W mojej opinii wyniki powtórzonych badań nad recepcją Wesela dziś także ujawniłyby podobne, znaczne problemy widzów z dookreśleniem faktów i postaci. 
Inny problem związany z praktyką badań odbioru stanowi uzyskanie wartościowego materiału do analiz. Już sama sytuacja wywiadu, proces ankietowania odgrywa dużą rolę. Istotny może być wpływ rozmówcy, odczytanie nastawień badacza względem badanych. Wśród podstawowych czynników determinujących proces zebrania danych od respondentów należy wymienić różny stopień kompetencji lingwistycznych, kulturowych, społecznych. Problemy z ujęciem doświadczeń odbioru w wywiadzie są nieobce także osobom posługującym się rozwiniętym kodem językowym, co pociąga za sobą konstatację o obiektywnych trudnościach badań nad odbiorem, nad recepcją filmów. Takie przypadki można zaobserwować $\mathrm{w}$ relacjach $\mathrm{z}$ wywiadów przeprowadzonych po projekcji filmowej Tulipanów (2004) w reżyserii Jacka Borcucha. Badani odbiorcy, głównie łódzcy studenci, różnili się poziomem umiejętności lingwistycznych oraz audiowizualnych (jedni znali lepiej język ruchomych obrazów niż inni), jednak lepsze kompetencje dwojakiego rodzaju nie niwelowały problemów $z$ odsłonięciem interpretacji przekazu czy deklaracji badanych co do ich własnych odczuwalnych, świadomościowych interpretacji o tym procesie, jakim jest odbiór filmu (Wejbert-Wąsiewicz 2017, s. 134-136, 141). Pewne aspekty tych interpretacji, czyli przeżyć odbiorców, pozostały całkiem nieznane, gdyż nie ujawniono ich $\mathrm{w}$ rozmowie. Socjologom wypada się pogodzić $z$ faktem, że interpretacja słowna dzieła nigdy nie jest adekwatna do całości przeżycia. Czasem odbiorca może chcieć zachować prywatne odczucia tylko dla siebie.

Innym zagadnieniem jest pomiar „niezrozumienia filmu” i dotarcie do przyczyn tego stanu. Egzemplifikację mogą stanowić dwie prace badawcze. Jacek Ostaszewski (1999) w latach dziewięćdziesiątych XX wieku podjął analizę prac pisemnych polonistów oraz kandydatów na studia filmoznawcze, aby zrekonstruować zjawiska rozumienia opowiadania filmowego $\mathrm{w}$ świetle kognitywnej teorii filmu, a Bogusław Skowronek wykorzystując kognitywną teorię filmu w pracy Konceptualizacje filmu i jego ogladania $w$ języku młodzieży (2007) nakreślił złożony obraz oczekiwań młodzieży wobec filmów, negocjowania i nadawania znaczeń filmowych, praktyk (np. odbiór kultowy) oraz indywidualnych gustów filmowych. Wyniki obu badań wskazują na powszechność niezrozumienia filmów w pełni, co świadczy raczej o skalarności niż binarności (zrozumienie versus niezrozumienie) tego zjawiska. Skowronek (2007, s. 176-199, 230) podkreśla, za Johnem Fiske, że młodzi mają świadomość komercyjnego nastawienia „sztuki filmowej”, a sami uprawiają „semiotyczną partyzantkę”, sprzeciwiając się dominującym znaczeniom filmowym, korzystają z filmów po swojemu. Ostaszewski i Skowronek zastosowali technikę badawczą opartą na słowie 
pisanym, zbierając prace licealistów i studentów. Drugi z autorów przeprowadził także ankietę oraz wywiady w klasach szkolnych. Socjologowie korzystali również z wypracowań, nierzadko łącząc to z innymi technikami pozyskiwania świadectw odbioru filmu, najczęściej z ankietami, z testami wiedzy i wywiadami indywidualnymi, rzadziej z obserwacjami.

Antonina Kłoskowska analizowała społeczne procesy interpretacji przekazów kultury symbolicznej. Zapoczątkowała takie analizy już w latach pięćdziesiątych ubiegłego wieku w odniesieniu do badań odbioru literatury. Dla jej uczniów i uczennic semiotyczny i aksjologiczny wymiar podejmowanych zagadnień był tak samo ważny. Świadczy o tym zamiłowanie do badań odbioru komunikatów artystycznych, chęć wniknięcia w sferę wartości odczuwanych. Łódzcy socjologowie kultury i sztuki poruszali problematykę otwartości dzieła, jego niejasności i niejednoznaczności, kwestie denotacji i konotacji ${ }^{11}$ (zob. Kłoskowska 1983, s, 409-411), „kodów” (nadawcy, odbiorcy, dzieła). Rejestrowali deklaracje dotyczące znajomości dzieł i ich rozumienia, interpretacji, akceptacji oraz wartościowania, podejmowali także trud wniknięcia w procesy świadomościowe odbiorców. Pozostawało to charakterystycznym znakiem badań empirycznych samej Kłoskowskiej prowadzonych w odniesieniu do sztuk fabularnych, na przykład potoczny odbiór dzieł Żeromskiego (zob. Kłoskowska 1976, s. 76-77). Wymagało zakorzenienia w teorii semiotycznej, fenomenologicznej oraz projektowania badań jakościowych nastawionych na triangulację danych.

Ilustrację procedury badawczej stanowić może projekt Mieczysława Gałuszki, który w latach dziewięćdziesiątych badał odbiór i znaczenie seriali. Serial był wtedy, jak pisał (Gałuszka 1996, s. 7), „, najbardziej popularnym gatunkiem telewizji i jej wizytówką propagandową". Wykorzystując różne techniki badawcze autor zamierzał odpowiedzieć na dwa podstawowe pytania: „co ludzie robią z telewizją, serialami” oraz „co telewizja, seriale robią z ludźmi". Projekt badań empirycznych objął: widzów brazylijskiej telenoweli Niewolnica Isaura (1976), emitowanej w Polsce w roku 1985 (50 wywiadów swobodnych oraz 288 prac pisemnych, wypowiedzi studentów); młodych widzów polskiego serialu Quo vadis (2002) w reżyserii Jerzego Kawalerowicza (155 studentów - test wiedzy historyczno-literackiej oraz pisemne prace na temat adaptacji filmowej Quo vadis); fanki amerykańskiej opery mydlanej Dynastia (60 wywiadów swobodnych z kobieta-

${ }^{11} \mathrm{~W}$ procesie percepcji filmów odmiennych kulturowo, obcych widz wychwytuje bezpośrednie znaczenia denotacyjne na podstawie własnych doświadczeń, sensy konotacyjne natomiast omija lub zastępuje własnymi. 
mi, które obejrzały prawie wszystkie odcinki, uzupełnionych o obserwacje uczestniczące przy wspólnym oglądaniu serialu); studentów medycyny (118 badanych - test wiedzy kulturowej oraz wypracowania na temat wzoru osobowego lekarza w serialu telewizyjnym $z$ lat dziewięćdziesiątych Przystanek Alaska). Autor przeprowadził ponadto dwadzieścia obserwacji podczas oglądania seriali w małych grupach. W efekcie ustalił typy odbiorców i modele odtworzenia filmu ${ }^{12}$. Zaproponował cztery typy odtworzeń:

(1) odtworzenie preferowane - gdy znaczenia dekodowane są zgodne z zawartym $w$ serialu modelem widza implikowanego;

(2) odtworzenie negocjowane - gdy odbiorca rozpoznaje punkt widzenia nadawcy, języki, schematy, koncepcje, ale akcentuje własną perspektywę odtworzenia treści, która jest zgodna z jego przekonaniami i wartościami;

(3) odtworzenie opozycyjne - sprzeczne z poglądami odbiorcy, „socjalizacja negatywna", odbiorca przypisuje dziełu sensy, które redefiniują znaczenie i wartości zawarte przez nadawcę;

(4) odtworzenie negatywne - gdy odbiorca jako widz obrazów nie potrafi dokonać identyfikacji tożsamości, kody odbiera sprzecznie, co prowadzi do zniekształceń obrazu (Gałuszka 1996, s. 74-75).

Antonina Kłoskowska rozróżniła odtworzenie potoczne i odtworzenie krytyczne w latach siedemdziesiątych ubiegłego wieku. Inspirowała się myślą Romana Ingardena ${ }^{13}$ odnośnie do konkretyzacji dzieła, ale jej termin cechowało głębsze znaczenie. „Odtworzenie” odnosiło się zarówno do intelektualnej, emocjonalnej, jak i aksjologicznej reakcji odbiorcy na dzieło. Nieco później pisała w Socjologii kultury (1983, s. 419):

„Odbiorca przekazu dokonujący jego dekodowania w sposób swoisty dla siebie i swej społecznej kategorii odtwarza go odwołując się przy tym do różnych warstw własnej osobowości, różnych czynników swego społecznego położenia i momentów aktualnej sytuacji odbiorczej. Pojęcie odtworzenia obejmuje wszystkie kategorie semiotycznej reakcji i podkreśla czynną rolę podmiotu w procesie komunikowania".

Metoda semiotyczna polegająca na traktowaniu przedmiotów, zjawisk jako znaków zyskała szerokie zainteresowanie, a wśród socjologów kul-

12 „Odtworzenie” okazało się ważnym pojęciem operacyjnym. Wykorzystywali je także Bogusław Sułkowski (1972), a także Ewelina Wejbert-Wąsiewicz (2017) w analizie materiału otrzymanego $\mathrm{w}$ ramach prowadzenia filmowego eksperymentu percepcyjnego.

13 Analogie i różnice pomiędzy „odtworzeniem” (Kłoskowskiej) a interpretacją (Ingardena) omawia Jan Grad (1997, s. 47-50). 
tury stała się istotną perspektywą teoretyczno-empiryczną. Zasługi nie do przecenienia ma w tym względzie Antonina Kłoskowska, także w odniesieniu do badań filmu. W jej ujęciu kultura symboliczna to kultura znaków i wartości. Najlepszym wskaźnikiem wielkości uczonego wydaje się stworzenie szkoły rozumianej jako twórcze dziedzictwo myśli i praktyki. Wypada dopowiedzieć, że Bogusław Sułkowski utworzył w łódzkim Instytucie Socjologii w 1994 roku Katedrę Socjologii Sztuki ${ }^{14}$, która zinstytucjonalizowała wyłoniony przez Kłoskowską obszar badawczy. Zespół skupiał się na badaniu społecznego funkcjonowania sztuki (plastyki, muzyki, teatru, filmu, fotografii). Nie zostały tu wymienione wszystkie prace autorów z łódzkiego ośrodka ukierunkowanych przez socjologię kultury Antoniny Kłoskowskiej, lecz trzeba zaznaczyć, że wszyscy badacze kultury symbolicznej byli nastawieni na odczytywanie sensów, znaczeń dzieł i wnieśli znaczący wkład do polskiej socjologii sztuki, socjologii literatury, socjologii filmu, socjologii teatru, socjologii wizualnej.

\section{BIBLIOGRAFIA}

Aumont Jacques, Marie Michel, 2012, Analiza filmu, tłum. Maria Zawadzka, Wydawnictwo Naukowe PWN, Warszawa.

Bokszański Zbigniew, 2012, Antoniny Kłoskowskiej teoria i socjologia kultury, „Przegląd Socjologiczny", nr 3.

Eco Umberto, 1972, Pejzaż semiotyczny, tłum. Adam Weinsberg, Państwowy Instytut Wydawniczy, Warszawa.

Fledelius Karlsten, 1981, Uwagi o analizie treści filmów i programów telewizyjnych, „Kino”, nr 3.

Gadamer Hans Georg, 2004, Prawda i metoda - zarys hermeneutyki filozoficznej, tłum. Bogdan Baran, Wydawnictwo Naukowe PWN, Warszawa.

Gałuszka Mieczysław, 1984a, Potoczne odtworzenie filmu, „Studia Socjologiczne”, nr 4.

Gałuszka Mieczysław, 1984b, Wzory osobowe w przekazach masowych. Przykład odbioru bohatera filmowego, „Przekazy i Opinie”, nr 1.

Gałuszka Mieczysław, 1987, Świadomość historyczna publiczności a procesy recepcji filmu, „Kultura i Społeczeństwo", nr 3.

Gałuszka Mieczysław, 1993, Serial telewizyjny i powieść w odbiorze potocznym, „Kultura i Społeczeństwo", nr 1.

Gałuszka Mieczysław, 1996, Między przyjemnościa a rytuałem. Serial telewizyjny w kulturze popularnej, Wydawnictwo Akademii Medycznej, Łódź.

Gałuszka Mieczysław, Kowalewicz Kazimierz, 1977, Szkic do badań potocznego odbioru filmu, „Kino”, nr 11.

Gałuszka Mieczysław, Kowalewicz Kazimierz, 1979, Studenci jako odbiorcy kultury, „Dydaktyka Szkoły Wyższej”, nr 3.

${ }^{14}$ W 2016 roku KSS stała się częścią Katedrą Socjologii Sztuki i Edukacji. Szerzej zob. http://instytutsocjologii.uni.lodz.pl/instytut/katedry-i-zaklady/katedra-socjologii-sztuk i-e dukacji/. 
Gałuszka Mieczysław, Kowalewicz Kazimierz, 1988, Kultura — selekcja - zapominanie, „Kultura i Społeczeństwo", nr 1.

Golka Marian, 1996, Socjologiczny obraz sztuki, Ars Nova, Poznań.

Grad Jan, 1997, Badania uczestnictwa w kulturze artystycznej w polskiej socjologii kultury, Wydawnictwo UAM, Poznań.

Has-Tokarz Anita, 2007, Między stowem a obrazem: afliacje literatury i filmu (perspektywa komparatystyczna), „Folia Bibliologica”, nr 48-49.

Helman Alicja (red.), 1991, Historia semiotyki filmu, t. 1, Zakład Semiotyki Logicznej UW, Polskie Towarzystwo Semiotyczne, Warszawa.

Helman Alicja (red.), 1992, Panorama wspótczesnej myśli filmowej, Universitas, Kraków.

Helman Alicja (red.), 1993, Historia semiotyki filmu, t. 2, Zakład Semiotyki Logicznej UW, Polskie Towarzystwo Semiotyczne, Warszawa.

Helman Alicja, 1976, Refleksje teoretyczne: Jezzk filmu w perspektywie semiotycznej, „Kino”, nr 3.

Helman Alicja, Ostaszewski Jacek (red.), 2007, Historia myśli filmowej. Podręcznik, Słowo/obraz/terytoria, Gdańsk.

Hendrykowski Marek, 2014, Semiotyka ruchomych obrazów, Wydawnictwo UAM, Poznań.

Ingarden Roman, 1972 [1958], Kilka uwag o sztuce filmowej, w: Alicja Helman (red. ), Estetyka i film, Wydawnictwa Artystyczne i Filmowe, Warszawa.

Jackiewicz Aleksander, 1975, Antropologia filmu, Wydawnictwo Literackie, Kraków.

Jakobson Roman, 1960, Poetyka w świetle językoznawstwa, tłum. z ang. Krystyna Pomorska, Ossolineum, Wrocław.

Kłoskowska Antonina, 1956, Autor, publiczność, cenzura (Wokót warszawskiego wydania „Pism” A. Mickiewicza z 1858 r.), „Nauka Polska”, z. 2-3.

Kłoskowska Antonina, 1976, Potoczny odbiór literatury na przykładzie utworów Żeromskiego, „Pamiętnik Literacki", nr 67/1.

Kłoskowska Antonina, 1983 [1981], Socjologia kultury, Państwowe Wydawnictwo Naukowe, Warszawa.

Kłoskowska Antonina, 1992, Potoczny odbiór i funkcje literatury, w: Zofia Mitosek (red.), Mimesis $w$ literaturze, kulturze $i$ sztuce, Państwowe Wydawnictwo Naukowe, Warszawa.

Kłoskowska Antonina, Rokuszewska-Pawełek Alicja, 1977, Mity literackie w świadomości potocznej: (przykład potocznego odbioru Wesela), „Kultura i Społeczeństwo”, nr 1.

Koprowska Teresa, 1986, Odbiór przekazu literackiego i telewizyjnego - zapamiętywanie i zapominanie treści w miarę uptywu czasu (wstępne wyniki badania eksperymentalnego), „Przekazy i Opinie", nr 1.

Kowalewicz Kazimierz, 1978, Notatki do szkicu o odbiorze filmów na przykładzie „Prześwietlenia” Krzysztofa Kieślowskiego, „Przekazy i Opinie”, nr 4.

Kowalewicz Kazimierz, 1993, Teatr i odbiorca. Przygotowanie do teorii odbioru przedstawienia teatralnego, Wydawnictwo Uniwersytetu Łódzkiego, Łódź.

Łotman Jurij, 1983, Semiotyka filmu, tłum. Jerzy Faryno, Tadeusz Miczka Wiedza Powszechna, Warszawa.

Łotman Jurij, 2008, Uniwersum umystu. Semiotyczna teoria kultury, tłum. Bogusław Żyłko, Wydawnictwo Uniwersytetu Gdańskiego, Gdańsk.

Markiewicz Henryk (oprac.), 1976, Współczesna teoria badań literackich za granica, t. 3, Wydawnictwo Literackie, Kraków. 
Matuchniak-Krasuska Anna, 1984, O interpretacji obrazu. Socjologiczne studium recepcji malarstwa, „Kultura i Społeczeństwo”, nr 2.

Matuchniak-Krasuska Anna, 1988, Gust i kompetencja. Społeczne zróżnicowanie recepcji malarstwa, Wydawnictwo Uniwersytetu Łódzkiego, Łódź.

Matuchniak-Krasuska Anna, 1999, Publiczność wobec metafory plastycznej. O recepcji groteski Jerzego Dudy-Gracza, Wydawnictwo Uniwersytetu Łódzkiego, Łódź.

Matuchniak-Krasuska Anna, 2012, Pamiątki $i$ wspomnienia o Profesor Antoninie Kłoskowskiej, „Przegląd Socjologiczny”, nr 3.

Mencwel Andrzej (red.), 1977, W kręgu socjologii literatury, t. 1, Państwowy Instytut Wydawniczy, Warszawa.

Olszewski Jan, 1978, Próba bilansu. Rozmowa z prof. Antoniną Kłoskowską, „Film”, nr 24.

Ostaszewski Jacek, 1999, Rozumienie opowiadania filmowego, Wydawnictwo Uniwersytetu Jagiellońskiego, Kraków.

Pelc Jerzy, 1982, Wstęp do semiotyki, Wiedza Powszechna, Warszawa.

Plesnar Łukasz, 1990, Semiotyka filmu, Wydawnictwo Uniwersytetu Jagiellońskiego, Kraków.

Płażewski Jerzy, 2008, Język filmu, Książka i Wiedza, Warszawa.

Ricoeur Paul, 1975, Egzystencja i hermeneutyka. Rozprawy o metodzie, tłum. Ewa Bieńkowska i in., PAX, Warszawa.

Rokuszewska-Pawełek Alicja, 1983, Potoczny odbiór literatury popularnej na przykładzie społecznej recepcji powieści kryminalnej, „Kultura i Społeczeństwo”, nr 1.

Skowronek Bogusław, 2007, Konceptualizacje filmu i jego ogląania w jęzku młodzieży. Studium kognitywno-kulturowe, Wydawnictwo Naukowe Akademii Pedagogicznej, Kraków.

Sławiński Janusz (red.), 1971, Problemy socjologii literatury, Ossolineum, Wrocław.

Sułkowski Bogusław, 1972, Powieść i czytelnicy. Społeczne warunkowanie odbioru, Państwowe Wydawnictwo Naukowe, Warszawa.

Sułkowski Bogusław, 1984, Zabawa. Studium socjologiczne, Państwowe Wydawnictwo Naukowe, Warszawa.

Wejbert-Wąsiewicz Ewelina, 2017, Bez retuszu czy po liftingu? Obrazy starości i aborcji w filmie, Wydawnictwo Uniwersytetu Łódzkiego, Łódź.

Zimnica-Kuzioła Emilia, 2003, Światła na widownię. Socjologiczne studium publiczności teatralnej, Wydawnictwo Uniwersytetu Łódzkiego, Łódź.

Żygulski Kazimierz, 1966, Socjologia filmu: elementy socjologii kultury i socjologii filmu, Wydawnictwa Artystyczne i Filmowe, Kraków.

\title{
THE ŁÓDŹ SCHOOL OF THE SOCIOLOGY OF CULTURE: FROM STUDYING THE RECEPTION OF VERBAL ART TO STUDYING THE RECEPTION OF VISUAL ART
}

\author{
Ewelina Wejbert-Wąsiewicz \\ (University of Łódź)
}

\section{Abstract}

For several decades of the last century, semiotic arrangements enriched the sociology of culture. The aim of the article is to show the achievements of the empirical school of sociology of culture in the perspective of the significant semiotic 
issues on the example of selectively selected works of the eminent scientist Antonina Kłoskowska and the "Łódź school" which she created. Thanks to Antonina Kłoskowska, the empirical way of the "Łódź school" sociology of culture led from literature reception research to visual arts research. Her students made a significant contribution to Polish sociology of art, sociology of literature, sociology of film, sociology of theater, and visual sociology. The text attempts to sketch semiotic theoretical inspirations, a characteristic theoretical and methodological approach to the study of symbolic culture. The problems of research on the reception of works were described in the context of selected studies on film reception. The starting point was the empirical research of Antonina Kłoskowska regarding the reception of the screening of the Wedding (dir. A. Wajda, 1973).

Key words / słowa kluczowe

Antonina Kłoskowska, sociology of culture / socjologia kultury, semiotic / semiotyka, symbolic culture / kultura symboliczna, Łódź School Sociology of Culture / łódzka szkoła socjologii kultury, film sociology / socjologia filmu 